\title{
EDUCOMUNICAÇÃO: CONTRIBUIÇÃO AO ENSINO E APRENDIZAGEM ${ }^{1}$ EDUCOMUNICATION: CONTRIBUTION TO TEACHING AND LEARNING
}

\author{
Cristiano de Souza Oliveira ${ }^{2}$ e Taís Steffenello Ghisleni ${ }^{3}$
}

\section{RESUMO}

Unir os conhecimentos da Educomunicação e, a partir deles, propor estratégias que contribuam para uma comunicação mais efetiva dentro do ambiente escolar é um desafio, e este artigo será focado nas discussões pertinentes que possam ampliar o desenvolvimento do ensino com as contribuições da Educomunicação auxiliando a Educação no contexto da COVID-19 e da globalização. Isso posto, o objetivo desse texto é expor os fundamentos da Educomunicação e suas práticas educomunicativas para sejam reconhecidos na relação da comunicação e educação também como um campo de intervenção no ensino intensificadas pela necessidade de distanciamento presencial em contextos como o da pandemia da COVID-19. A metodologia incluiu pesquisa exploratória e bibliográfica, de natureza qualitativa e nossos resultados reforçam que o conhecimento não pode ser entendido apenas como algo a ser transmitido pelos educomunicadores aos educomunicandos, mas sim algo a ser construído.

Palavras-chave: Educação; Comunicação; COVID-19.

\section{ABSTRACT}

Uniting the knowledge of Educommunication and based on it, proposing strategies that contribute to a more effective communication within the school environment is a challenge and this article will focus on relevant discussions that can expand the development of teaching with the contributions of Educommunication helping Education in the context of COVID-19 and globalization. That said, the purpose of this text is to expose the fundamentals of Educommunication and its educommunicative practices to be recognized in the relationship of communication and education also as a field of intervention in teaching intensified by the need for faceto-face distance in contexts such as the pandemic of COVID-19. The methodology included exploratory and bibliographic research, of a qualitative nature and our results reinforce that knowledge cannot be understood only as something to be transmitted by educommunicators to educomunicandos, but rather to be constructed.

Keywords: Education; Communication; COVID-19.

\footnotetext{
${ }^{1}$ Trabalho de pesquisa vinculado a dissertação de mestrado em andamento.

${ }^{2}$ Graduado em Matemática. Aluno do Mestrado em Ensino de Humanidades e Linguagens - Universidade Franciscana. E-mail: csooliveira80@gmail.com

${ }^{3}$ Professora na Universidade Franciscana (Santa Maria, RS), nos cursos de Mestrado em Ensino de Humanidades e Linguagens, e graduação em Publicidade e Propaganda. Doutora em Comunicação pela Universidade Federal de Santa Maria (UFSM), Mestre em Engenharia de Produção (UFSM), Especialista em Ciência do Movimento Humano (UFSM), e Bacharel em Comunicação Social, Publicidade e Propaganda (UNIJUÍ). Pesquisador Líder no Grupo de Pesquisa CNPq: Mídia e Processos Sócio-Culturais. E-mail: taisghisleni@yahoo.com.br
} 


\section{INTRODUÇÃO}

No dia 11 de março de 2020, o diretor-geral da Organização Mundial da Saúde (OMS), Tedros Adhanom, declarou que a organização elevou o estado de contaminação pelo novo coronavírus como pandemia (AGÊNCIA BRASIL, 2020). O ensino inserido no cenário de transformações políticas, econômicas, sociais e principalmente com a inserção da pandemia, está enfrentando desafios no sentido de inovar e acompanhar a evolução de professores e alunos na busca por uma educação de qualidade. Isso também passa pela busca de meios que aproximem o aluno do professor e vice-versa, já que essa situação interrompeu as aulas presenciais por um período muito maior do que se pudesse imaginar.

Dessa forma as reflexões em torno de melhores práticas de ensino na relação entre professores e alunos têm aumentado, pois não estão relacionadas apenas ao olhar pedagógico, ao conhecimento e à compreensão de seu significado. Elas precisam ser inseridas em uma perspectiva mais abrangente, que envolva o distanciamento presencial de alunos e professores fisicamente nas salas de aula com a utilização de mídias e comunicação, indispensáveis em uma sociedade globalizada na qual a educação escolar é tida como fator central para o desenvolvimento socioeconômico e a ascensão social, já que temos um mundo com grandes desigualdades sociais onde a tecnologia não é um privilégio e nem é acessível a todos.

Mas o ensino não ocorre apenas na presença da tecnologia, as aprendizagens ocorrem no cotidiano de todos os alunos, nas suas vivências e experiências. Os mesmos trazem para as aulas um conjunto de atitudes que expressam seus pensamentos e conceitos, decorrentes das oportunidades vivenciadas nos diferentes grupos. No entanto, para que uma pessoa aprenda é preciso que ela esteja aberta às percepções e às diferenciações. No âmbito da educação não se aprende apenas através da memorização dos temas, das exposições do professor ou do acúmulo de conhecimento dos fatos (ROGERS, 1971).

O processo de educação que é vivido pelo aluno fica em um clima de crescimento mútuo, pois o professor, ao mostrar certas situações facilita esse crescimento, deixando de ser a tradicional figura que centraliza o conhecimento ou que detém o saber, para compartilhar essa busca com seu aluno, vindo ambos a aprender. A ação pedagógica baseada neste princípio compreende que os alunos, que serão incentivados e desafiados pelo professor, possuem um potencial cognitivo e afetivo a ser desenvolvido no processo, e que está relacionado com o trabalho do professor, a fim de que possam crescer e integrar-se no contexto sociocultural ao qual pertencem (GUEDES, 1981).

Brandão (1981) já afirmava que não existem apenas um formato ou modelo de educação e que ela faz parte do imaginário social para transformar o mundo e seus sujeitos em algo melhor. Com base nesta afirmação, é possível dizer que a educação tem influência em todas as áreas de nossa vida, sendo um direito fundamental que além de auxiliar o crescimento individual também pode ajudar no desenvolvimento do país, auxiliando o crescimento profissional. Não há quem possa dizer que não teria 
benefícios se tivesse estudado um pouco mais, quando se depara com uma sociedade competitiva, onde o ambiente se modifica velozmente (LOTÉRIO, 2009).

Lotério (2009, online) também afirmava que "quanto mais as pessoas estudarem, mais oportunidades terão no mercado de trabalho". E que as pessoas que concluem seus cursos de pós-graduação têm muito mais chances de conseguir um emprego do que quem não se alfabetizou. Sendo assim, a educação é primordial para o crescimento do povo brasileiro como um todo, já que em nosso mundo globalizado cada um de nós acaba competindo ou mostrando suas habilidades em qualquer parte da terra. Com o crescimento na qualidade da educação obtemos também um melhor aproveitamento das oportunidades no cenário mundial nos levando a pensar em competência global como o conjunto de conhecimentos, habilidades e motivações para investigar o mundo, reconhecer diferentes perspectivas, comunicar ideias e se tornar agente de mudanças na sociedade (LOTÉRICO, 2009).

Portanto, se a educação é fundamental para o desenvolvimento global, a comunicação é essencial nesse processo. Bordenave (1997, p. 17) explica que "a comunicação foi o canal pelo qual os padrões de vida de sua cultura foram-lhe transmitidos, pelo qual aprendeu a ser "membro" de sua sociedade de sua família, de seu grupo de amigos, de sua vizinhança, de sua nação”. Soares (2000, p. 18) reflete que no início, "o homem estabeleceu processos de comunicação entre si, usando para isso recursos diferentes" daqueles utilizados na educação. E esses processos tiveram muitos conflitos com o ambiente educacional, até que o contexto foi se modificando e entrou em cena "um novo campo de intervenção social a que denominamos de inter-relação comunicação/educação" (SOARES, 2000, p. 21), que vem a ser a Educomunicação.

Para auxiliar nessas conexões um novo campo teórico-prático começa a ser discutido, avaliado e aos poucos invade o meio educacional, discutido e vem se tornando essencial no ambiente acadêmico e escolar: a "Educomunicação". Como a evolução da tecnologia privilegia as relações de comunicação mundial, a escola precisa utilizar todos os recursos possíveis para promover o fluxo informativo entre seus membros e suas conexões com o meio externo em que estão inseridos, assim como em suas relações internas.

Atualmente quando falamos que o aprendizado na escola deve ser entendível a todos, a aliança com as tecnologias e às suas formas de se comunicar tem sido a solução encontrada e imposta as escolas, já que a pandemia da COVID-19 afastou alunos e professores da convivência física diária, e colocou a comunicação digital como primordial na agilidade das trocas de informações escolares e nas plataformas, como smartphones, tablets e computadores e lançou um desafio que não será pauta de discussão nesse artigo que é de como disponibilizar a todos o acesso a essas ferramentas digitais.

Portanto com a vivência nesse ano de 2020 de um cenário mundial de pandemia do Coronavírus que não imaginávamos passar por esse desafio que perdura já muito além das perspectivas iniciais, com o desafio de nos mantermos com saúde, unidos e encontrarmos o equilíbrio no cenário econômico, social e no ensino passou a ser o foco principal de discussão mundialmente. Mediante a 
contextualização mencionada o ensino apresenta uma demanda urgente pela inserção da Educomunicação no ambiente escolar, já que temos uma realidade de docentes e discentes principalmente da rede pública de ensino que não estão conseguindo manter e transmitir uma educação de qualidade seguindo o cronograma dos conteúdos de ensino pela falta de habilidades da maioria dos professores, pais e também dos alunos, nas plataformas, e de acesso a uma estrutura adequada de computador e internet.

A partir do contexto exposto, unir os conhecimentos da Educomunicação e, a partir deles, propor estratégias que contribuam para uma comunicação mais efetiva dentro do ambiente escolar é um desafio e este artigo será focado nas discussões pertinentes que possam ampliar o desenvolvimento do ensino com as contribuições da Educomunicação auxiliando a Educação no contexto da COVID-19 e da globalização. Assim o objetivo desse texto é expor os fundamentos da Educomunicação e suas práticas educomunicativas para sejam reconhecidos na relação da comunicação e educação também como um campo de intervenção no ensino intensificadas pela necessidade de distanciamento presencial em contextos como o da pandemia da COVID-19.

Como primeira proposição desse texto é preciso ter claro que as práticas educomunicativas incluem a inserção de ferramentas pedagógicas como vídeo, rádio, blog, jornal nas práticas de ensino e aprendizagem, buscando auxiliar na comunicação da educação e dessa forma otimizar todo o processo de ensino, na relação entre docentes e discentes construindo ecossistemas educomunicativos que promovam a cidadania, e evolução do ensino aprendizagem, partindo do pressuposto que o conhecimento não pode ser entendido apenas como algo a ser transmitido pelos educomunicadores aos educomunicandos, mas sim algo a ser construído.

\section{ASPECTOS METODOLÓGICOS}

Este artigo utilizou a pesquisa bibliográfica para a compreensão dos fundamentos da Educomunicação e suas práticas educomunicativas no ambiente escolar intensificado pelo distanciamento presencial imposto pela pandemia da COVID-19 para buscar entender a possibilidade do reconhecimento da Educomunicação na relação de comunicação e educação no ensino.

\section{O CONCEITO DE EDUCOMUNICAÇÃO}

Soares (2003) define a Educomunicação como um conjunto de ações que objetiva ampliar o coeficiente comunicativo das atividades educativas, no desenvolvimento das habilidades de expressão dos membros das comunidades educativas e de sua competência no manejo das tecnologias da informação e da comunicação. Assim todas as práticas Educomunicativas devem estarem incluídas em um ecossistema de Comunicação. Soares (2003) agrega o ecossistema de Comunicação com o conceito na perspectiva da gestão comunicativa, onde o ecossistema comunicacional designa a organização do 
ambiente, a disponibilização dos recursos, e o conjunto das ações que caracterizam determinado tipo de ação comunicacional.

Continuadamente o ambiente escolar deixou de ser o exclusivo fornecedor de conhecimento e orientação de conteúdo para as crianças e adolescentes, se acelerando nos últimos anos. O desenvolvimento de novas tecnologias eletrônicas e a facilidade de acesso a elas, junta-se à crescente presença da mídia no cotidiano das pessoas, e por isso é muito importante refletir sobre a comunicação, mídia, educação, a Educomunicação, como meio facilitador do entrosamento social e das práticas pedagógicas na escola. Essa relação Mídia-Educação é definida por Gonet (2004) como uma educação crítica para a leitura das mídias, qualquer que seja o suporte, com o objetivo de facilitar um distanciamento, pela tomada de consciência do funcionamento das mídias, tanto de seus conteúdos como da contextualização dos sistemas no qual elas evoluem.

Fantin (2011), defende a Mídia-Educação em sua utilização crítica, criativa e cultural das tecnologias pelo professor para propiciar a interação e a apropriação ativa do conhecimento pelo aluno, na perspectiva de articular os direitos de proteção, provisão e participação. Leva-se em consideração que existe integração entre Comunicação e Educação e a utilização das mídias sob o olhar pedagógico ganha uma perspectiva própria, elaborando um campo de intervenção social específico denominado de "Educomunicação". O conceito indicado se trata de uma metodologia pedagógica que propõe o uso de recursos tecnológicos modernos e técnicas da comunicação na aprendizagem através de meios de mídia realizando a interdisciplinaridade (SOARES, 2004).

A aprendizagem de acordo com Skinner (1972) é denominada como o processo de aquisição de conhecimentos, habilidades, valores e atitudes, possibilitado através do estudo, do ensino ou da experiência, onde um sujeito aprende quando produz modificações no ambiente, significando que algo de novo lhe foi ensinado de forma a se tornar mais adaptativo, passando então a emitir um novo comportamento pelo indivíduo.

Neste processo de aprendizagem o professor é a peça principal na condução e, portanto é preciso enfatizar que ser docente é ter a capacidade de contribuir com a formação acadêmica, profissional e pessoal dos discentes, os quais "vão se transformando em reais sujeitos da construção e reconstrução do saber ensinado, ao lado do educador igualmente sujeito do processo" (FREIRE, 1996, p. 26), ou seja, ensina ao passo que também comunica e aprende, consequentemente, ambos devem estar presentes em todo processo educativo e comunicativo.

Complementando o conceito entende-se Educomunicação como

[...] o conjunto das ações inerentes ao planejamento, implementação e avaliação de processos e produtos destinados a criar e fortalecer ecossistemas comunicativos em espaços educativos, melhorar o coeficiente comunicativo das ações educativas, desenvolver o espírito crítico dos usuários dos meios massivos, usar adequadamente os recursos da informação nas práticas educativas, e ampliar capacidade de expressão das pessoas (SOARES, 2003, p. 01). 
Dessa forma a importância desta discussão para o ensino dialogando com as contribuições conceituais já desenvolvidas nos trabalhos de Educomunicação está sendo muito discutido, utilizando mídias e comunicação envolvidas nas práticas pedagógicas docentes. A Educomunicação acompanha os fatos do dia a dia dos alunos, muito além de apenas o apresentado nos livros didáticos. O surgimento do coronavírus, por exemplo, não está registrado nos livros, mesmo os mais atualizados e com isso, os estudantes têm a oportunidade de abordarem temas de repercussão global que estão em seu contexto, de forma crítica, utilizando recursos muito mais interessantes e dinâmicos do que os tradicionais utilizados em sala de aula, como as diversas reportagens de sites na internet, as reportagens da TV, dos jornais. Pinheiro (2016, p. 240) reforça que "a Educomunicação sustenta o diálogo, o espaço para o conhecimento crítico e criativo, para a cidadania e a solidariedade presente em todos os processos de ensino-aprendizagem seja em âmbito formal, informal ou não formal”.

Os temas abordados podem variar de acordo com a disciplina, como: meio ambiente, escassez e desperdício de água, causas indígenas, matemática e física aplicadas no dia a dia, geografia, história, línguas, informática etc. Com isso, as escolas podem desenvolver um projeto anual, envolvendo todas as disciplinas, com a participação de todas as turmas, a fim de retratar algum assunto importante para a população (BARROS, 2020).

Soares (2002) explica ainda que a Educomunicação é capaz de absorver os fundamentos do campo da Educação, da Comunicação e até de outros campos das Ciências Sociais e isso faz com que seja capaz de superar as barreiras epistemológicas impostas pela visão iluminista e funcionalista que faz com que os campos tradicionais do saber sejam tão isoláveis e pouco comunicativos. Sendo assim, a Educomunicação é um conceito em permanente construção e que está preparado para atravessar as mudanças tecnológicas e sociais a que estamos sendo submetidos o tempo todo.

Neste contexto de utilização da Educomunicação na escola como alternativa de transformação desse espaço tornando-o muito mais dinâmico, atrativo e inserido em seu contexto de vivência diária, suas aplicações ainda têm grandes desafios de inserção nos conteúdos curriculares, o repensar das práticas de ensino aprendizagem que auxiliem na comunicação entre todos os fatores que colaboram com a educação e o reconhecimento de seus potenciais agentes fomentadores desse processo, tempos e espaços torna-se fundamental para oportunizar outras possibilidades educativas (SOARES, 2002).

Assim, a educação é cada vez mais tensionada a estabelecer diálogo com outras áreas do conhecimento, em arranjos mais abertos, criativos, participativos e que buscam, sobretudo, não hierarquizar a distribuição do saber, possível a qualquer pessoa, dado o seu reconhecimento, mas que venham auxiliar no processo de ensino do currículo através de ferramentas utilizadas no cotidiano discente que contribuam para melhorar a qualidade do ensino.

Essa é a defesa da Educomunicação, que vem mostrando como o uso dos meios, linguagens e ferramentas de comunicação podem estar presentes no espaço escolar, garantindo não só o direito universal à comunicação, mas também outras possibilidades de aprendizagem. 
A Educomunicação é entendida como uma nova área de conhecimento à medida que ela se apresenta como uma interface entre a educação e a comunicação. É um campo de estudo que propõe uma reflexão acerca da mediação da comunicação e das mídias nos mais diversos processos de ensino e aprendizagem, propondo uma aprendizagem colaborativa, sustentada principalmente pelos processos de comunicação ofertados pelas Tecnologias da Informação e Comunicação (TICs) (SOARES, 2011).

$\mathrm{Na}$ Educomunicação acontece a união do ensino, da educação com os meios de comunicação que atingem um grande público, por exemplo, rádio, televisão, jornal e internet, e consiste num conceito com metodologia e pedagogia próprio que possibilita a construção destes ecossistemas comunicativos entre os participantes e o conteúdo que transmitem ao público.

Com a Educomunicação é possível criar e fortalecer os ecossistemas comunicativos supracitados em espaços educativos, melhorando o coeficiente comunicativo das ações educativas, e dessa forma é possível desenvolver o espírito crítico dos usuários dos meios massivos e usar adequadamente os recursos da informação nas práticas educativas, vindo a ampliar a capacidade de expressão das pessoas (SOARES, 2003).

Para Soares (2011) a Educomunicação é um campo de pesquisa, reflexão e intervenção social, cujos objetivos, conteúdos e metodologia são essencialmente diferentes tanto da educação escolar como da comunicação social. Nessa visão podemos afirmar que a Educomunicação é o resultado de um projeto transdisciplinar.

Para entendimento do conceito transdisciplinar, Limaverde (2012) se refere a transdisciplinaridade como um conceito mais amplo onde o prefixo trans quer dizer aquilo que está entre, através e além. Um ensino transdisciplinar não se restringe nem à simples reunião das disciplinas nem à possibilidade de haver diálogo entre duas ou mais disciplinas. A transdisciplinaridade faz com que o tema pesquisado passe pelas disciplinas, sem ter como objetivo final o conhecimento específico dessa mesma disciplina ou a preocupação de delimitar o que é o seu objeto de estudo ou o que é de outra área inter-relacionada. A transdisciplinaridade se preocupa com a interação contínua e ininterrupta de todas as disciplinas num momento e lugar.

E continuando ao entendimento da Educomunicação em uma concepção transdisciplinar em seu artigo “Mas, afinal, o que é Educomunicação?” o professor Ismar de Oliveira Soares (2010), do Núcleo de Comunicação e Educação da Universidade de São Paulo (NCE/USP), um dos pioneiros na área de Educomunicação no Brasil, além de definir a Educomunicação, afirma que para acontecer sua excelência a mesma necessita que sejam observados alguns procedimentos sem o quais fica irreconhecível, e entre eles destaca:

a) É necessário prever e planejar \'conjuntos de ações〉', no contexto do plano pedagógico das escolas, e não ações isoladas (uma ação isolada não modifica as relações de comunicação num ambiente marcado por práticas autoritárias de comunicação);

b) Todo planejamento deve ser participativo envolvendo todas as pessoas envolvidas como agentes ou beneficiárias das ações (por isso, convidamos os professores, alunos e membros das comunidades a desenvolverem planejamentos conjuntos); 
c) As relações de comunicação devem ser sempre francas e abertas (a Educomunicação busca rever os conceitos tradicionais de comunicação, como se existisse apenas para persuadir ou fazer a boa imagem dos que detêm poder e fama. Aqui, a comunicação é feita para socializar e criar consensos);

d) O objetivo principal é o crescimento da autoestima e da capacidade de expressão das pessoas, como indivíduos e como grupo (SOARES, 2010 p. 01).

Além disso, a Educomunicação tem como objetivo caracterizar uma nova proposta de intervenção e de reflexão das relações didáticas nos seus diferentes aspectos epistemológicos e técnicos, pois dessa forma é possível viabilizar que haja comunicação entre as pessoas e principalmente no meio acadêmico de forma mais democrática, sendo totalmente possível a atuação da escola de tempo integral e no contraturno. (LUVIZOTTO; ALANIZ; ANNIBALL, 2017).

\section{Educomunicação em seu contexto atual}

Para entender o a importância da Educomunicação no contexto atual é preciso mencionar que quem a criou foi a sociedade civil, junto às organizações não governamentais, vinculadas essencialmente à defesa da cidadania e dos direitos humanos. A academia a sistematizou, e isso significa dizer que o conceito não nasceu em consequência da aplicação de resultados de pesquisas à realidade social, mas emergiu das práticas de agentes comunitários que, nos meados do século XX, que buscavam soluções para seus problemas de comunicação. Uma vez identificada e sistematizada, foi possível à academia propor a prática educomunicativa a diferentes âmbitos sociais, entre os quais o midiático e o educativo (SOARES, 2014).

Especialistas conhecedores das linguagens da comunicação e da intencionalidade educativa da América Latina, países Ibérios e Estados Unidos, como Kaplún, promoveram, ao longo dos anos 1960 a 1990, projetos de intervenção com profunda incidência social, como por exemplo assuntos relacionados à ecologia, a defesa da democracia e principalmente o que o remete à periferia da América Latina, especialmente no período compreendido entre as décadas de 1960 e 1970, momento em que os principais países do continente viviam sob a opressão de ditaduras militares, com restrições à circulação de informações (SOARES, 2014).

Para Freire, a educação deve se constituir como uma estratégia de compartilhar conhecimento, ocorrendo simultaneamente no professor e aluno. “O educador já não é mais o que apenas educa, mas o que, enquanto educa, é educado, em diálogo com o educando que ao ser educado, também educa. (...) Os homens se educam em comunhão, mediatizados pelo mundo" (FREIRE, 1978, p. 39).

Dessa maneira, essa prática de desenvolvimento da mídia faz com que se desenvolvam uma boa relação entre todos os integrantes do sistema, pois se não houver a discussão construtiva entre as pessoas, cada um acaba se isolando com seus pensamentos e ações em sua própria zona de conforto, o que reforça a importância da comunicação pessoal. Nesse contexto destaca-se o Mário Kaplún, 
argentino que não poupou esforços em aprofundar estudos e discussões contribuindo para o desenvolvimento da Comunicação Educativa com veículos alternativos de comunicação com abordagens em manifestações culturais como a música e a arte cênica.

E buscando ampliar o conhecimento no Brasil sobre o campo de estudo Soares (2014) salienta que foi feito um estado da arte sobre a Educomunicação que resultou em, na sequência, a tarefa de identificar o fato e de sistematizá-lo através do banco de teses da Capes ao informar que, entre o ano de 2000 e 2014, foram defendidas, no Brasil, 110 dissertações e teses doutorais sobre o conceito de Educomunicação, em centros de pós-graduação em Comunicação, em Educação e nas diferentes áreas das Ciências Humanas e Sociais.

Então do ponto de vista acadêmico a Educomunicação é um conceito que está consolidado como um paradigma que trabalha, reforça questões e propostas que a diferencia da educação tradicional ou comunicação tradicional principalmente por se ligar às Tecnologias da Informação e Comunicação (TICs).

As TICs no ambiente escolar devem servir como mais um recurso educacional nesse processo de ensino, pois possuem um grande potencial a favor da educação e exigem participação ativa de todos os sujeitos. A figura do professor assume o papel de mediador no processo de desenvolvimento de alunos críticos e participativos. Para que isso ocorra, alguns aspectos devem ser considerados. Conforme os Parâmetros Curriculares Nacionais (PCN),

\footnotetext{
Para garantir aprendizagens significativas, o professor precisa considerar a experiência prévia dos alunos em relação ao recurso tecnológico que será utilizado e ao conteúdo em questão; e organizar as situações de aula em função do nível de competência dos alunos. As aulas devem ser planejadas levando-se em consideração: os objetivos e os conteúdos de aprendizagem; as potencialidades do recurso tecnológico para promover aprendizagens significativas; os encaminhamentos para problematizar os conteúdos utilizando tecnologia; e os procedimentos da máquina que são necessários conhecer para sua manipulação (BRASIL, 1998, p. 153).
}

As Tecnologias da Informação e Comunicação (TICs) são consideradas uma das abordagens da Educomunicação na educação envolvendo os métodos de gerenciamentos dos fluxos de comunicação nos processos de ensino e aprendizagem, sendo utilizadas como ferramentas facilitadoras nesse processo e na pandemia da COVID-19 essencial, já que as escolas em curtíssimo espaço de tempo tiveram que implementar plataformas de ensino a distância, professores tiveram que romper com as barreiras de dificuldades de utilização das ferramentas digitais para se adaptar a um cenário que não proporcionou opções de tempo e longos treinamentos.

E esta evolução social e cientifica da Educomunicação centralizada nas relações de comunicação e educação ao longo do tempo é decisiva para entender os próprios modos de produzir, colocar em circulação e interagir com o conhecimento e as trocas informativas com os múltiplos planos e níveis estruturantes da vida social que passaram ao longo do tempo a elaborar os seus fluxos internos tendo como mediadores as possibilidades e mesmo facilidades permitidas pelas redes de computadores e novas tecnologias. 


\section{A EDUCOMUNICAÇÃO E SEUS DESAFIOS NA COMUNICAÇÃO}

O processo de globalização e a pandemia da COVID-19 em 2020 apresentaram a nossa sociedade a expansão e evolução dos meios de comunicação vindo a transformar e revolucionar a nossa relação com a informação, com o trabalho, a maneira como nos comunicamos com as pessoas e como aprendemos e ensinamos em nosso meio de convivência e um esforço muito maior dos entes públicos em investir em tecnologia aliada a educação com maior facilidade de acesso.

Com a globalização em geral já há muitos anos houve o processo de aproximação entre as diversas sociedades e nações existentes por todo o mundo, seja no âmbito econômico, social, cultural ou político e com a pandemia da COVID-19 as relações entre as diversos países do mundo se intensificaram. A globalização permitiu uma maior conexão entre pontos distintos do planeta, fazendo com que compartilhassem de características em comum, através da comunicação em um mundo globalizado onde tudo está interligado. Neste contexto a escola passa a ter novos desafios frente a esse novo cenário de integração globalizada, pois há várias formas de disseminar os saberes e isto resulta em modificar e utilizar dinamicamente as formas de se aprender e passar esses saberes no ambiente escolar.

A pandemia da COVID-19 distanciou alunos e professores do meio físico de sala de aula e ao mesmo tempo tornou essencial a presença da utilização dos meios digitais, para que a relação entre docentes e discentes continuassem e nesse processo a Educomunicação como um todo se tornou indispensável para que o processo de ensino e aprendizagem continuassem a acontecer de forma dinâmica, atrativa e principalmente eficiente.

Todo o processo de mudança no intuito de intensificar uma qualidade pedagógica no ensino está relacionado com as raízes mais profundas na educação e na emergência de novos paradigmas educacionais que se apresentam de forma diferente ao longo do tempo implementando, modificando novos cenários de convivência. Neste ambiente significativo que se apresenta a Educomunicação ancorada em duas áreas que já estão consolidadas: educação e comunicação ela vem se constituindo como um novo campo de produção de conhecimento.

Nesse sentido, a Educomunicação tem como premissa tentar humanizar as práticas educacionais e o exercício da cidadania, com perspectivas de elaborar ecossistemas com comunicação abertos e democráticos, permitindo a oportunidade da própria comunidade se expressar, seja na educação desenvolvida nas salas de aula das escolas, com seus devidos programas de ensino, seja na educação informal, que é aquela que ocorre nas relações das experiências cotidianas, principalmente desenvolvida em espaços abertos com a inclusão da comunidade em geral.

De acordo com a Associação Brasileira de Pesquisadores e Profissionais em Educomunicação - ABPducom- o lócus da prática educomunicativa é justamente a interface entre Comunicação/ Educação em um campo transdisciplinar de diálogo para que seja possível haver reflexões e ações de 
planejamento de utilização de ferramentas facilitadoras como a tecnologia, implementação de processos e produtos que sejam destinados à:

- à ampliação da capacidade de expressão de todas as pessoas em um dado contexto educativo, presencial ou virtual (tanto em práticas de ensino formal, quanto em experiências de educação não formal ou mesmo informal);

- à melhoraria do coeficiente comunicativo das ações educativas, convertendo-as em práticas de diálogo social, a serviço da cidadania;

- ao desenvolvimento de práticas de "literacia midiática", mediante exercícios que facilitem o entendimento e a análise do comportamento operacional dos meios de comunicação, bem como orientem o convívio com as mensagens midiáticas e seu uso no cotidiano da vida em sociedade; - ao emprego dos recursos da informação nas práticas educativas, numa perspectiva criativa e participativa.

- ao protagonismo comunicativo dos sujeitos, independentemente de suas condições de idade, gênero, nível econômico ou posição social. Visível nas ações do movimento social, em toda a América Latina, a partir dos anos de 1960, através da comunicação alternativa e de resistência, assim como da educação popular de viés dialógico, o conceito, sistematizado pelo NCE/USP, em 1999, tem como seu principal desafio, hoje, legitimar-se socialmente e converter-se em referencial para políticas públicas (ABPducom, 2019).

A Educomunicação é entendida e sistematizada pela ABPEducom como um paradigma orientador de práticas sócio-educativo-comunicacionais que têm como principal objetivo norteador de seu trabalho conduzir a criação e o fortalecimento de ecossistemas comunicativos abertos e democráticos nos espaços educativos, mediante a gestão compartilhada e solidária dos recursos da comunicação, suas linguagens e tecnologias, levando ao fortalecimento do protagonismo dos sujeitos sociais e ao consequente exercício prático do direito universal à expressão.

Rubim (2009) arrola os principais elementos que marcam esta realidade sociocomunicacional:

A expansão quantitativa da comunicação, em especial em sua modalidade midiatizada; a diversidade das novas modalidades de mídias presentes no espectro societário, ampliando a complexidade da 'ecologia da comunicação' (Moles, 1974); o papel desempenhado pela comunicação midiatizada como modo (crescente e até majoritário) de experenciar e conhecer a vida, a realidade e o mundo; a presença e abrangência das culturas midiáticas como circuito cultural hegemônico, que organiza e difunde socialmente comportamentos, percepções, sentimentos, ideários, valores, etc.; as ressonâncias sociais da comunicação midiatizada sobre a produção da significação (intelectiva) e da sensibilidade (afetiva), sociais e individuais; a prevalência da mídia como esfera de publicização hegemônica dentre os diferenciados 'espaços públicos' socialmente existentes, articulados e concorrentes; as mutações espaciais e temporais provocadas pelas redes midiáticas, na perspectiva de forjar uma vida planetária e em tempo real; o crescimento vertiginoso dos setores voltados para a produção, circulação, difusão e consumo de bens simbólicos; a ampliação (percentual) dos trabalhadores da informação e da produção simbólica no conjunto da população economicamente ativa e o aumento crescente das despesas com as comunicações, em suas diferenciadas modalidades (RUBIM, 2009 p. 105-106).

E é no interior destas interações das diversas modalidades de comunicação que as aproximações educomunicativas passam a terem sentido, onde tudo que se remete a educação, de maneira particular aquela de natureza formal, está relacionada pelas iterações comunicacionais e com elas 
mantém determinados vínculos, diálogos, tensões, interlocuções. Estas interações sobrelevam-se, contudo, nas salas de aula, nas relações entre docentes e discentes.

Fígaro (2010) aponta que se deve prestar atenção nestas relações onde:

a escola precisa estar consciente dos fatores que a envolvem, ou seja, formar para o mercado competitivo, orientado pela lógica do mais forte, ou formar cidadãos para sociedade democrática e de oportunidade para todos? Buscar o equilíbrio entre esses dois aspectos é tarefa complicada, mas urgente. E é no trabalho com comunicação/educação que se poderá enfrentar de maneira mais explícita tal desafio (FÍGARO, 2010, p. 10).

E este desafio na educação de fazer com que a comunicação seja fortalecida entre os professores e alunos na construção do conhecimento, pode ser facilitada com a inserção da mídia no ambiente escolar.

De acordo com Guazina (2007) no campo da Comunicação a palavra mídia apesar de ser bem utilizada, é difícil ter um conceito que seja consenso entre os pesquisadores, pois sua utilização até 2004 faz parte de uma extensão ou decorrência natural de um conjunto de meios de comunicação. Dentre vários conceitos do que significa mídia, destaca-se o conceito de Lima (2004) que segundo ele, mídia pode ser entendida como

\begin{abstract}
o conjunto de instituições que utiliza tecnologias específicas para realizar a comunicação humana. Vale dizer que a mídia implica na existência de um intermediário tecnológico para que a comunicação se realize. A comunicação passa, portanto, a ser uma comunicação mediatizada. Este é um tipo específico de comunicação que aparece tardiamente na história da humanidade e se constitui em um dos importantes símbolos da modernidade. Duas características da mídia são a sua unidirecionalidade e a produção centralizada e padronizada de conteúdos. Concretamente, quando falamos da mídia, estamos nos referindo ao conjunto das emissoras de rádio e de televisão (aberta e paga), de jornais e de revistas, do cinema e das outras diversas instituições que utilizam recursos tecnológicos na chamada comunicação de massa (LIMA, 2004, p. 113).
\end{abstract}

A mídia é um veículo, espaço ou canal onde uma mensagem é transmitida, ou seja o conteúdo apresentado parte do emissor em direção ao interlocutor e tem o objetivo de estabelecer certo nível de comunicação.

Em termos gerais, as mídias de acordo com Pires (2020) dependem do tipo de comunicação que se pretende criar, onde se o desejo for por uma comunicação verbal, oral, as mídias incluem conversas presenciais, o telefone e assim por diante, mas se o desejo for por uma comunicação escrita envolve meios como revistas, jornais ou qualquer tipo de publicação.

Dentre todos os tipos de mídia que são utilizados atualmente, o uso da tecnologia está presente na maioria delas e essa é uma tendência que veio para ficar, se diferenciando entre mídias analógicas e digitais.

As primeiras estabelecem uma comunicação unilateral, em que somente o emissor da mensagem fala com o interlocutor. É o que acontece quando vemos um anúncio na TV ou nos deparamos com uma propaganda em um outdoor no meio da cidade. Já as mídias digitais 
permitem uma comunicação direta e até em tempo real. Quando uma empresa pública nas redes sociais, o público pode interagir e responder à postagem. Isso garante uma troca bilateral, além de favorecer o acompanhamento e até a automação (PIRES, $2020 \mathrm{~s} / \mathrm{p}$ ).

Segundo Franco, Braga e Rodrigues (2010, p. 16), essas ferramentas de mídias proporcionam: a interação por meio de atividades síncronas e assíncronas, entre alunos/conteúdos, alunos/formadores, formadores/alunos e alunos/alunos; o compartilhamento de informações pessoais e profissionais (que constam num perfil, por exemplo): conhecimento prévio das experiências pessoais, profissional, línguas e culturas dos alunos e dos professores; a troca de ideias entre professores e alunos; a participação em discussões temáticas (conduzidas ou não), a valorização da adversidade, das diferenças, etc.; o desenvolvimento de trabalhos em grupos; o compartilhamento entre colegas de trabalhos individuais, e, a construção do conhecimento do aluno com a colaboração dos outros participantes do grupo.

Aprofundando o tema, Braga (2011) destaca que em seus estudos o que interessa mais que o conceito de mídia, é uma abordagem voltada para o entendimento da "midiatização", pois este enfatiza expressamente processos segundo os quais “as mídias funcionam”, mas também pelo quais a sociedade contemporânea historicamente aciona suas interações. Ou seja: a midiatização como processo comunicacional da sociedade, mais que como "ação das mídias" sobre a sociedade.

Luvizotto; Annibal; Alaniz; (2017) ressaltam que se trata de abordagens distintas e a principal diferença é de que em uma, a mídia-educação, as discussões se dão justamente da presença das mídias, integrando as relações didáticas pela ação docente; a outra, a Educomunicação, desenvolve a ideia de práticas educomunicativas que nem sempre necessitam integrar a escola formal e nem estar a cargo de um professor. Considera-se um profissional especializado: o educomunicador. Para Citelli (2000), os educomunicadores

[...] são profissionais que atentos aos problemas da educação, tendo ciência dos mecanismos didático-pedagógicos e dos propósitos formadores, não perdem de perspectiva as possibilidades facultadas pela comunicação (e seus dispositivos) e pelas novas tecnologias (CITELLI, 2000, p. 21).

O Educomunicador tem o perfil de gerenciar processos que se comunicam, como um profissional que tem conhecimento em relação as teorias e práticas da educação que envolvem o mundo da produção midiática e das tecnologias, exercendo atividades de caráter transdisciplinar tanto na docência quanto na coordenação de trabalhos de campo, relacionando comunicação/educação.

A Educomunicação é um processo educativo que permite aos alunos apropriarem-se criativamente dos meios de comunicação, no cenário atual que vivemos na era tecnológica, evidencia-se a mediação tecnológica na educação definido por Soares (2003) como um

campo de estudo que contempla a análise das mudanças decorrentes da incidência das inovações tecnológicas no cotidiano das pessoas e grupos sociais, assim como o uso das ferramentas da informação nos processos educativos, sejam os presenciais sejam os a distância. A preocupação 
com as tecnologias na educação tem sido estimulada, na verdade, tanto pelo avanço das experiências educacionais no campo da virtualidade tecnológica quanto pela mobilização governamental em torno da denominada "economia da informação" (SOARES, 2003 p. 6).

Para Moran, "cada docente pode encontrar sua forma mais adequada de integrar as várias tecnologias e os muitos procedimentos metodológicos. Mas também, é importante que amplie, que aprenda a dominar as formas de comunicação interpessoal/grupal e as de comunicação audiovisual/ telemáticas. (MORAN, 2000, p. 32). Nesta mesma linha de pensamento, Behrens (2000) discorre sobre o acesso à tecnologia:

Num mundo globalizado, que derruba barreiras de tempo e espaço, o acesso à tecnologia exige atitude crítica e inovadora, possibilitando o relacionamento com a sociedade como um todo. O desafio passa por criar e permitir uma nova ação docente na qual professor e alunos participam de um processo conjunto para aprender de forma criativa, dinâmica, encorajadora e que tenha como essência o diálogo e a descoberta (BEHRENS, 2000, p. 77).

Ao assumir essa postura, vai propiciar aos alunos a formação de sua identidade, o desenvolvimento de sua capacidade crítica, de sua autoconfiança e de sua criatividade (ALMEIDA, 2000, p. 79). E para auxiliar nesse processo de ensino aprendizagem é importante conhecer e dominar as ferramentas Educomunicativas que auxiliam no processo de comunicação no ambiente escolar.

\section{A EDUCOMUNICAÇÃO E SUAS FERRAMENTAS}

São várias as ferramentas que podemos utilizar para trabalhar com educomunicação, e entre essas, optamos por destacar: blogs educativos, produção radiofônica (rádio), construção colaborativa, questionários na web (games), fóruns de discussão, quadrinhos, vídeo, jornal, fanzines.

A inserção da produção do vídeo no ambiente escolar, como por exemplo os documentários, torna crianças, adolescentes e jovens mais críticos ao assistirem televisão, pois viveram a experiência de produzir aquela mídia e conhecem melhor seu potencial. O vídeo possibilita a desconstrução e a recriação da linguagem da televisão, tão presente na vida dos estudantes, além de ser um produto importante na construção da interdisciplinaridade, ou seja, exigem a aplicação de múltiplos saberes acadêmicos na sua elaboração (BRASIL, 2016).

Já a internet no ambiente educacional vem assumindo uma importante função de apoio pedagógico, como ferramenta educomunicativa de uma aprendizagem dinâmica. Porém, é importante enfatizar que este recurso não substitui a figura do docente, ele apenas auxilia no processo de ensino e aprendizagem. É necessário que o professor saiba utilizar essa ferramenta de maneira apropriada para o bom desempenho e eficácia de seu trabalho escolar.

Em relação ao emprego do jornal como meio de comunicação no ambiente escolar tem grande importância pois é visto como, "uma forma de exercício de poder, já que a autonomia do leitor e 
a possibilidade de um ecossistema comunicativo marcado pela dialogicidade implica a descentralização da palavra autorizada e a transformação das relações sociais internas do espaço escolar (SOARES, 2011, p. 24).

Já os games de acordo com Braga e Calazans (2001), são processos dialógicos direcionados e de retorno direto, uma vez que todos seus atos e ações recebem "feedbacks", ou seja, consequências imediatas associadas a estruturas imagéticas que o compõe com ícones de sucesso e derrota. Além disso, estando os jogos cada vez mais integrados frente às redes sociais, tornam-se eixo de comunicação não apenas direta, mas de valores, símbolos e atos promovidos pelo grupo que os acessa.

Também merece destaque os fanzines que são entendidos como uma ferramenta que reúne recursos para atrair os jovens à superação dos obstáculos na tarefa de ler e escrever, o fanzine também prevê a difusão de seus textos e esforços conjugados entre escrita e produção artística, o que assimila outras modalidades interpretativas. Zauith, Davanço e Barbieri (2019, p. 57) reforçam que "o fanzine propõe uma mudança do processo de comunicação tradicional, com produtores do processo produtivo, não somente como receptores de mensagens". Mas apesar de ser ter demonstrado a importância das ferramentas educomonunicativa, no seu entendimento e domínio nessas ferramentas e sua aplicação no ambiente escolar precisam ser reforçadas na formação docente, buscando nesse processo uma qualificação no ensino com integração e cooperação entre as disciplinas dos currículos escolares.

\section{CONSIDERAÇÕES FINAIS}

A partir do referencial teórico da Educomunicação é possível diagnosticar situações que consigam ampliar o coeficiente comunicativo do contexto educacional principalmente relacionado a importância da educomunicação com o distanciamento entre alunos e professores com a pandemia da COVID-19 que estão tendo que aprender a usar as tecnologias e as ferramentas educomunicativas para desenvolver os conteúdos programáticos e manter a atenção dos alunos nas telas dos computadores.

Entendendo esse aspecto principal, abre-se espaço para promover e programar ações que ampliem os ecossistemas comunicativos e que esses quebrem a hierarquia de distribuição do saber, colocando todos os participantes do processo em um mesmo nível para a troca de saberes, ou seja, construir um local no qual todos possam se expressar e comunicar de forma direta tanto no ambiente escolar físico como no ambiente virtual.

É importante destacar que o processo educomunicativo valoriza o processo de aprendizagem, e o profissional que trabalha com a Educomunicação é muito importante pois ele que vai dar vida aos processos comunicativos, sejam quais forem dentro das opções que são disponibilizadas. O formato utilizado em cada contexto vai depender da turma, da disponibilidade tecnológica, das ferramentas a que tem acesso no momento e com o distanciamento e as aulas online todo esse contexto está sendo fundamental para que os alunos se mantenham em segurança e consigam aprender e se comunicar. 
E neste contexto do ambiente escolar, seja ele físico ou virtual como se colocou o ensino com o Coronavírus, a Educomunicação aliada à tecnologia está sendo fundamental para realizar a conexão do ensino dos livros com o cotidiano dos discentes, os professores precisam utilizar os meios de comunicação, que chamamos de ferramentas educomunicativas, e estas colaboram para a disseminação e compartilhamento dos temas abordados em sala de aula.

As ferramentas educomunicativas, se bem utilizadas no ambiente escolar, podem facilitar um diálogo dinâmico-dialógico, no qual os discentes podem expor suas opiniões sobre as atividades e suas aprendizagens, assim como podem possibilitar a veiculação das produções permitindo a troca de ideias, entre os docentes e discentes de diferentes turmas, vindo a oferecer todas as vantagens de comunicação na busca da construção coletiva do conhecimento.

Após o entendimento dos fundamentos da Educomunicação, suas ferramentas educomunicativas e práticas, com suas inserções na qualificação do ensino seja ele presencial ou a distância, é possível afirmar que a Educomunicação é essencial para a intervenção no ensino e desenvolvimento das múltiplas inteligências de docentes e discentes nos levando a repensar o futuro da educação. Outro aspecto é a inclusão de uma articulação apropriada entre o Ensino a distância (EAD) e o Ensino presencial para construirmos um futuro mais saudável, próspero e seguro com políticas públicas que garantam um financiamento adequado para a Educação, fazendo uso inteligente das tecnologias disponíveis, priorizando os mais vulneráveis e protegendo educadores e alunos e fazendo com que a Educomunicação se concretize em sua real essência que é realizar a melhor comunicação possível para uma educação de qualidade.

Portanto conclui-se que é possível que os fundamentos da Educomunicação e de suas práticas educomunicativas sejam reconhecidos na relação da comunicação e educação como um novo campo de intervenção no ensino intensificadas pela necessidade de distanciamento presencial com a pandemia da COVID-19.

\section{REFÊRENCIAS}

ALMEIDA, M. E. B. de. ProInfo: Informática e Formação de Professores. v. 1. Série de Estudos Educação a Distância. Brasília: Ministério da Educação, Seed, 2000b.

\section{ABPEDUCOM. Associação Brasileira de Pesquisadores e Profissionais em Educomunicação.}

Disponível em: http://www.abpeducom.org.br/abpeducom. Acesso em: 03 nov. 2019.

BARROS, J. de. Educomunicação. Disponível em: https://educador.brasilescola.uol.com.br/. Acesso em: 04 fev. 2020. 
BRAGA, J. L. Constituição no Campo da Comunicação. Revista Verso e Reverso, v. 15, n. 58, p. 62-77, 2011. Disponível em: https://bit.ly/2XDp3Nt. Acesso em: 01 maio. 2019.

BRANDÃO, C. R. O que é educação. São Paulo: Brasiliense, 1981.

BRASIL. Ministério da Educação. Parâmetros Curriculares Nacionais. 2. Arte. Brasília: Secretaria de Educação Fundamental. - Brasília: MEC /SEF.1998.

CITELLI, A. Comunicação e Educação: a linguagem em movimento. São Paulo: Senac, 2000. 246 p.

FANTIN, M. Mídia-educação: aspectos históricos e teórico metodológicos. Revista Olhar de Professor, Ponta Grossa, v. 14, n. 1, p. 27- 40, 2011b. Disponível em: https://bit.ly/3oLF7Jd. Acesso em: 10 maio. 2019.

FÍGARO, R. Comunicação/educação: campo de ressignificação das tecnologias de comunicação. Comunicação \& Educação, v. 15, n. 3, p. 7-15, 2010. https://bit.ly/39ze2m8.

FRANCO, L. R. H. R.; BRAGA, D. B. e RODRIGUES, A.. EaD Virtual: entre a teoria e a prática. Ed. Premier; UNIFEI, 2010.

FREIRE, Paulo. Pedagogia da autonomia: saberes necessários à prática educativa. 1996. 43. ed., São Paulo: Paz e Terra. 148 p.

FREIRE, Paulo. Pedagogia do oprimido. Rio de Janeiro. Paz e Terra, 1978.

GARDNER, H. Estruturas da mente: A Teoria das Múltiplas Inteligências. Porto Alegre: Artes Médicas, 1995.

GONET, J. Educação e Mídias. São Paulo: Loyola, 2004.

GUAZINA, L. O conceito de mídia na comunicação e na política. Desafios interdisciplinares. Revista Debates, Porto Alegre, v. 1, n. 1, p. 49-64, 2007.

GUEDES, S. P. Educação, pessoa e liberdade: propostas Rogerianas para uma práxis psicopedagógica centrada no aluno. 2. ed. São Paulo: Moraes, 1981. 
LIMA, V. A. Sete teses sobre a relação Mídia e Política. Revista USP, São Paulo, n. 61, p. 48-57, mar./maio 2004. Disponível em: https://bit.ly/2LRmAfK. Acesso em: 12 dez. 2018.

LIMAVERDE, P. Parâmetros para Práticas Educativas Transdisciplinares 1.20 ago. 2012. Disponível em: https://bit.ly/39vCYuB. Acesso em: 02. Nov. 2019.

LOTÉRIO, A. Qual a importância da Educação? 2009. Disponível em: https://bit.ly/3nDxzXy. Acesso em: 25 fev. 2020.

LUVIZOTTO, C. Kr.; ALANiZ, E. P. i; ANNIBALL, S. F. MÍDIA-EDUCAÇÃO, EDUCOMUNICAÇÃO E FORMAÇÃO DE PROFESSORES. Revista Latinoamericana de Ciências de La Comunicación. V. 14, n. 26, 2017. Acesso em: 01 jun. 2019.

MORAN, J. M. et al. Novas tecnologias e mediação pedagógica. 6. ed. Campinas: Papirus, 2000.

AGÊNCIA BRASIL. Organização Mundial da Saúde declara pandemia de coronavírus. 11/03/2020. Disponível em: https://bit.ly/2LNM9yo. Acesso em: 9 Dec. 2020.

PINHEIRO, R. M. A Contribuição da Educomunicação para o Ensino Superior. Revista Observatório, v. 2, n. 2, p. 327-344, 30 maio 2016.

ROGERS, C. R. Liberdade para aprender. Belo Horizonte: Interlivros, 1971.

RUBIM, A. A. C. Políticas culturas e novos desafios. Revista Matrizes, São Paulo, Ano 2, n. 2, jan/jun 2009.

SKINNER, B. Tecnologia do Ensino. São Paulo: Herder; 1972.

SOARES, I. de O. Alfabetização e Educomunicação O papel dos meios de comunicação e informação na educação de jovens e adultos ao longo da vida. In: III Telecongresso Internacional de Educação de Jovens e Adultos. 2003. Disponível em: https://bit.ly/38Jfx1J. Acesso em: 20 out. 2019.

SOARES, I. de O. Mas afinal, o que é Educomunicação? 2004. Disponível em: https://bit.ly/39BZ9zz. Acesso em: 05 maio. 2019. 
SOARES, I. de O. Ecossistemas Comunicativos, 2010. Disponível em: https://bit.ly/2Lrj3VU. Acesso em: 25/abril/2015.

SOARES, I. de O. Educomunicação: o conceito, o profissional, a aplicação: contribuições para a reforma do ensino médio. São Paulo: Paulinas, 2011.

SOARES, I. de O. Educomunicação: um campo de mediações. Comunicação \& Educação, n. 19, p. 12-24, 2000. Disponível em: https://bit.ly/3qldUNU. Acesso em: 10 dez. 2020.

SOARES, I. de O. Educomunicação e Educação Midiática: vertentes históricas de aproximação entre Comunicação e Educação. Comunicação \& Educação, Ano XIX, número 2, jul/dez 2014. Disponível em: https://bit.ly/3bGL1rg. Acesso em: 15 out. 2019.

SOARES, I. de O. Gestão comunicativa e educação: caminhos da educomunicação. Comunicação \& Educação, [S. l.], n. 23, p. 16-25, 2002. Disponível em: https://bit.ly/2N5qOkJ. Acesso em: 9 dez. 2020.

ZAUITH, G.; DAVANÇO, Â. R.; BARBIERI, M. R. Oficina de fanzine: práticas de educomunicação com alunos da Casa da Ciência. Comunicação \& Educação, v. 24, n. 1, p. 56-68, 2019. DOI: 10.11606/ issn.2316-9125.v24i1p56-68. Disponível em: https://bit.ly/2LzcLmT. Acesso em: 02 dez. 2020. 
